from the udder. ${ }^{11}$ Some pathogens are inactivated during the cheese making process (this depends on the temperature and $\mathrm{pH}$ during production and ripening), but many can survive. ${ }^{12}$ Clearly the process in itself cannot be relied upon to eliminate them; adequate pasteurisation is therefore the logical first stage in the manufacture of cheese.

According to Desenclos et al, "pasteurisation of raw milk cheeses is not feasible for cultural, social, and economic reasons."' Is this really true? Much of the excellent traditional cheese from France and other countries is made from pasteurised milk. Many cheese makers who produce prize winning gourmet cheeses use pasteurised milk because they know that the product will not only be safe but also free from bacteria and yeasts, which may spoil the flavour or produce gas. Is the notion that raw milk cheese tastes better just a myth? Is it really possible to taste the difference? Even if it is, is it worth risking peoples' health or even their lives? Recent European legislation prescribes strict microbiological standards for milk and dairy products and reflects current anxieties about the microbiological safety of cheese..$^{13}$ Because of the difficulty of obtaining adequate representative samples, however, testing of the end product is notoriously insensitive as a method for detecting intermittent contamination with pathogens. As these recent outbreaks show, the damage is already done by the time a problem is detected.

There are no restrictions on the sale of foods made from raw milk in any country in the European Union. Nor is there any obligation to state on the retail label that the product is made from raw milk. Thus the advice from Desenclos et al that highly vulnerable groups of people (such as infants, pregnant women, and elderly and immunocompromised people) should avoid these cheeses is impractical. Surely it would be better to ensure that pasteurisation is the first stage in the production of all milk products. This together with adequate control of hygiene throughout the process would ensure that all cheeses could be relied upon as delicious, safe, and nutritious foods.

Public Health Laboratory,

ANITA RAMPLING

Department of Pathology,

West Dorset Hospital,

Dorchester DT1 2JY

1 Desenclos JC, Bouvet P, Benz-Lemoine E, Grimont F, Desqueyroux H, Rebière, et al. Salmonella enterica serotype paratyphi $B$ in goat milk cheese, France, 1993. BMf 1995;311:91-4

2 Goulet V, Jacquet C, Vaillant V, Rebière I, Mouret E, Lorente C, et al. Listeriosis from consumption of raw-milk cheese. Lancet 1995;345:1581-2.

3 Two clusters of haemolytic uraemic syndrome in France. Commun Dis Rep Weekly 1994;4:29.

4 Brucellosis associated with unpasteurised milk products abroad. Commun Dis Rep Weekly 1995;5:151.

5 Curnow J. E coli 0157 phage type 28 infections in Grampian. Commun Dis Rep Weekly 1994;28:1. (No 94/46.)

6 Maguire H, Boyle M, Lewis MJ, Pankhurst J, Wieneke AA, Jacob M, et al. A large outbreak of food poisoning of unknown aetiology associated with stilton cheese. Epidemiol Infect 1991;106: 497-505.

7 Maguire H, Cowden J, Jacob M, Rowe B, Roberts D, Bruce J, et al. An outbreak of Salmonella dublin infection in England and Wales associated with a soft unpasteurized cows' milk cheese. dublin infection in England and

8 Johnson EA, Nelson JH, Johnson M. Microbiological safery of cheese made from heat-treated milk. Part II. Microbiology. Foumal of Food Protection 1990;53:519-40.

9 Linnan MJ, Mascola L, Lou XD, Goulet V, May S, Salminen C, et al. Epidemic listeriosis associated with Mexican-style cheese. N Engl f Med 1988;54:823-8.

10 McLauchlin J, Greenwood MH, Pini PN. The occurrence of Listeria monocytogenes in cheese from a manufacturer associated with a case of listeriosis. Int f Food Microbiol 1990;10:255-62.

11 Rampling A. The microbiology of milk and milk products. In: Linton AH, Dick HM, eds. Topley and Wilson's principles of bacteriology, virology and immunity. Vol 1. 8th ed. London: Edward Arnold, 1990:265-89.

12 Chapman HR, Sharpe ME. Microbiology of cheese. In: Robinson RK, ed. Dairy microbiology Vol 2. 2nd ed. London: Elsevier Applied Science, 1990:203-89.

13 European Council directive $92 / 46 / \mathrm{EEC}$. Laying down the health rules for the production and placing on the market of milk and milk-based products, as amended by council directives 92/118/EEC and 94/71EC. Official foumal 1994;No L268:1. (14 September 1992.)

\title{
Third generation oral contraception and venous thromboembolism
}

\section{The published evidence confirms the Committee on Safety of Medicine's concerns}

Eighteen weeks ago, Britain's Committee on Safety of Medicines raised concerns about the newest brands of oral contraceptive pill, ${ }^{1}$ responding to new evidence that pills containing desogestral and gestodene conferred a two times greater risk of venous thromboembolism than pills containing other progestagens. At the time, none of the data on which the committee's announcement was based had been published. Dissatisfied doctors, anxious patients, and hundreds of column inches in the press were the natural consequence of this imposed uncertainty. ${ }^{2}$ Data from three case control studies, one of them nested in a cohort study, have since been published, ${ }^{3-6}$ and this week's $B M \mathcal{F}$ carries two papers reporting data from a third case control study ( $\mathrm{pp} \mathrm{83,} \mathrm{88).{ } ^ { 7 8 }}$

The studies published in December were a subanalysis of data from the large WHO study of women in 10 countries exposed to third generation oral contraceptive pills ${ }^{34}$; a casecontrol study of current users of the oral contraceptive pill from the British general practice research databases; and a reanalysis of the Leiden thrombophilia study. ${ }^{6}$ All studies indicated a statistically significant doubling of the adjusted odds ratios for venous thromboembolism in patients taking third rather than second generation oral contraceptive pills. These results are consistent with those from the transnational study published in this issue of the $B M \mathcal{F}$. The increased risk cannot be explained by known or expected bias or confounding.

The first law of epidemiology is that if a causal effect is large enough, it will show up despite all the problems of performing, analysing, and interpreting observational studies on real people. The recent studies are a case in point. Despite their different designs (with different funding arrangements) and different populations, they show a similar size and direction of effect. The doubling of risk of venous thromboembolism in users of third generation pills is important when the baseline risk in users of the pill is already three times greater than in non-users. Some studies have reported a relative risk of venous thromboembolism of about 9 for users of third generation pills compared to women using nonhormonal contraception, ignoring high risk subgroups. ${ }^{47}$ Fortunately, venous thromboembolism remains rare among young women, but any added risk is crucial when treating healthy women and when balancing risks against possible benefits such as protection against myocardial infarction.

The effects of third generation oral contraceptive pills on the incidence of myocardial infarction remain uncertain and will now be difficult to study. The paper by Lewis et al shows that the reduction in incidence of nearly threefold among users of third compared to second generation oral contraceptive pills is not statistically significant, and there is no apparent difference with third generation pills compared to non-hormonal contraception. ${ }^{8}$ These results suggest that third generation pills may, in the long term, be beneficial, but such preliminary data cannot provide a reliable basis for policy decisions on safe contraception. The finding was not confirmed by Jick et $a,^{5}$ and in view of the committee's pronouncement, further studies of third generation 
oral contraceptive pills in unselected women seem unlikely.

Now that the data are published, it seems clear that the Committee on Safety of Medicines did what it had to do. Delaying its announcement until all the studies had been published would have incurred a further 500000 uninformed woman years of use of the third generation oral contraceptive pills, which might have resulted in 80 new cases of venous thromboembolism and possibly one death. We have no clear idea how many women responded to the committee's advice and in what way, so these numbers are speculative, but the number of additional unwanted pregnancies, and related cases of venous thromboembolism, will appear in official statistics in a few months' time. The cost in terms of anxiety and the new side effects from switching over to second generation pills cannot yet be measured. However, the committee's advice should have included, for all the data available, simple standardised point estimates of risk (with corresponding confidence intervals) for second and third generation oral contraceptive pills. People would then have been able to assess the nature and consistency of the evidence for themselves.

From the four studies we now have a pooled estimate of relative risk of venous thromboembolism in unselected women of around $2 \cdot 0$ (95\% confidence interval $1 \cdot 4$ to $2 \cdot 7)$. We also have important data, from the second paper published in this issue ${ }^{8}$ and from other studies, ${ }^{9}$ that the greatest risk to health comes from smoking while taking the pill, rather than from the type of pill being used. Young women smokers who use the pill are 10 times more likely to suffer myocardial infarction than users who don't smoke (odds ratio $10 \cdot 1 ; 5 \cdot 7$ to 17.9). ${ }^{8}$ This risk is higher among users of second than third generation pills, but the difference, unfortunately for those who believe that third generation pills improve the lipid profile, is not statistically significant. During the next century, large numbers of young women will certainly die from smoking related diseases; about half of regular smokers will die prematurely from their addictive habit. ${ }^{10}$ Although the secretary of state for health, Stephen Dorrell, felt unable to ignore the expert advice from the Committee on Safety of Medicines, he continues to ignore the published advice of his own department's report. " By his prompt action, he may have prevented one death from venous thromboembolism, but he will not be around to count the cost of his government's inaction in vital areas of tobacco policy.

Now that the dust has settled, the message for doctors seems clear: when advising patients on which pill to take, a careful personal and family history for increased risk of venous thromboembolism is essential, followed where appropriate by screening for thrombophilia. Women with risk factors for venous thromboembolism should probably not start taking third generation pills; but once informed of the small excess risk, women already taking them satisfactorily may choose to continue using them. Let us hope that any disproportionate fear of litigation soon gives way to intelligent and well informed collaborative decision making.

KLIM MCPHERSON

Professor of public health epidemiology

Health Promotion Sciences Unit,

Department of Public Health and Policy,

London School of Hygiene and Tropical Medicine,

London WC1E 7HT

1 Department of Health. New advice on oral contraceptives. London: DoH, 1995

2 Carnall D. Controversy rages over new contraceptive data. $B M \mathcal{F}^{1}$ 1995;311:1117-8.

3 Poulter NR, Chang CL, Farley TMM, Meirik O, Marmot MG. Venous thromboembolic disease and combined oral contraceptives: results of international multicentre case-control study. Lancet 1995;346:1575-82.

4 Farley TMM, Meirik O, Chang CL, Marmot MG, Poulter NR. Effect of different progestagens in low oestrogen oral contraceptives on venous thromboembolic disease. Lancet 1995;346:1582-8.

5 Jick H, Jick SS, Gurewich V, Myers MW, Vasilakis C. Risk of idiopathic cardiovascular death and non-fatal venous thromboembolism in women using oral contraceptives with differing progestagen components. Lancet 1995;346:1589-93.

6 Bloemenkamp KWM, Rosendaal FR, Helmerhorst FM, Buller HR, Vandenbroucke JP. Enhancement by factor V Leiden mutation of risk of deep-vein thrombosis associated with oral contraceptives containing third-generation progestagen. Lancet 1995;346:1593-6.

7 Spizzer WO, Lewis AL, Heinemann LAJ, Thorogood M, MacRae KD on behalf of Transnational Research Group on Oral Contraceptives and the Health of Young Women. Third generation oral contraceptives and risk of venous thromboembolic disorders: an international case-control study. $B M F$ 1996;312:83-8.

8 Lewis AL, Spitzer WO, Heinemann LAJ, MacRae KD, Bruppacher R, Thorogood M on behalf of Transnational Research Group on Oral Contraceptives and the Health of Young Women. Third generation oral contraceptives and risk of myocardial infarction: an international case-control study. $B M F$ 1996;312:88-90.

9 Stadel BV. Oral contraceptives and cardiovascular disease. N Engl F Med 1981;305:612-8.

10 Peto R. Smoking and death: the past 40 years and the next 40. BMF 1994;309:937-9.

11 Smee C. Effects of tobacco advertising on tobacco consumption. London: Department of Health, 1992.

\section{Men's health}

\section{Unhealthy lifestyles and an unwillingness to seek medical help}

Differences in men's and women's health experience and behaviour are well recognised. ${ }^{1}$ Although policy makers have focused for some years on women's health, men's health has been less well defined. There are now signs that the profile of men's health is growing. Increased interest is expressed in, for example, the 1992 annual report by England's chief medical officer $^{2}$; a national conference held in London in July; and increasing media coverage is reflected in the growth of men's health magazines.

The growing interest has largely concentrated on aspects of men's health relating to diseases of the prostate and testicle. This sex specific approach encourages comparisons with the women's health movement, with campaigns for national screening programmes for prostatic and testicular cancer analogous to the screening programme for breast cancer. Such an approach has its place. Prostate disease is extremely common, but there is little agreement about effective treatment. ${ }^{3}$ Half of all men have benign prostatic hyperplasia by the time they are 60 years old, and $90 \%$ by the time they are
85. Prostate cancer is the second commonest cancer in men in Britain and the numbers diagnosed are increasing, particularly in older men. Occult cancer exists in about $30 \%$ of men over 50 and there is currently no way of distinguishing which tumours will remain dormant and which will metastasise rapidly. The much vaunted test for prostatic cancer, prostate specific antigen, is not sufficiently sensitive or specific to be effective as a diagnostic screening tool. ${ }^{4}$ Similarly, population based screening for testicular cancer has not been recommended, even though it is the commonest cancer in men in Britain aged 20-34 and early treatment has good results. There are, however, good arguments to support campaigns to raise awareness, such as the Cancer Research Campaign's "Keep your eye on the ball," which was launched in September 1995.

Although much needs to happen in such sex specific areas of men's health, concentrating on these areas ignores the important effects of psychosocial pressures on men within modern society. Statistics show that men are likely to die 